\title{
Sudden Deafness
}

\author{
Dra Mirta D’Ambra* \\ University of Buenos Aires, Public Health Specialist U.B.A, Argentina
}

Submission: October 23, 2018; Published: October 30, 2018

*Corresponding author: Dra Mirta D’Ambra, FWAMS M.D Head Hospital Argerich Ministry of Health of the Nation UBA, University of Buenos Aires, Public Health Specialist U.B.A, Argentina

\section{Abstract}

Sudden loss of hearing is a severe sensorineural hearing loss that develops in a few hours or is noticed upon awakening. It affects about 1 / 5,000 to 1 / 10,000 people per year. At the beginning, hearing loss is typically unilateral (unless induced by drugs) and may vary in intensity from mild to profound. Many people have tinnitus and some dizziness or vertigo. Sudden hearing loss has some causes that differ from chronic hearing loss and should be treated urgently

\section{Etiology}

The following are common features of sudden deafness:

a) In most cases, sudden deafness is idiopathic.

b) Some occur in the course of an obvious event that explains it.

c) In some cases, it represents the initial manifestation of a hidden but identifiable disorder.

\section{Idiopathic}

There are numerous theories for which there is some evidence (although conflicting and incomplete). Possibilities include viral infections (especially herpes simplex), autoimmune crises, and acute microvascular occlusion.

\section{Obvious Event}

Some causes of sudden deafness are easily evident. Bruised cranioencephalic trauma with fracture of the temporal bone or severe concussion affecting the cochlea can cause sudden hearing loss.

a) Large changes in ambient pressure: For example, those caused by diving or vigorous activities (eg, weight washing) that can induce a peri lymphatic fistula between the middle and inner ear, which causes severe and sudden symptoms. The peri lymphatic fistula can also be congenital; spontaneously it can cause sudden loss or loss can occur as a result of trauma or severe pressure changes.

b) Ototoxic drugs can cause hearing loss, in some cases in a day, especially with an overdose (administered systemically or when applied over a wide wound, as in the case of a burn). There is a rare mitochondrial genetic disorder that increases the susceptibility to ototoxicity by aminoglycosides. c) Lyme disease and many viral infections that affect the cochlea (and sometimes the vestibular apparatus). The most frequent viral causes in developed countries are mumps and herpes. Measles is a very rare cause, since most of the population is vaccinated.

d) Hidden Disorders: Sudden hearing loss is rarely the first isolated manifestation of some disorders that usually have other initial symptoms. For example, sudden hearing loss can rarely be the first manifestation of an acoustic neuroma, multiple sclerosis, Manières disease or a small cerebellar vascular accident. Reactivation of syphilis in patients infected with HIV rarely causes sudden hearing loss.

e) Cogan syndrome is a rare autoimmune reaction directed against an unknown common autoantigen in the cornea and inner ear; $>50 \%$ of patients present with vestibuloauditic symptoms. From 10 to $30 \%$ of patients, it also has severe systemic vasculitis, which may include life-threatening aortitis.

f) Some vasculitic disorders can cause hearing loss, in some cases acute. Blood disorders, such as Waldenström's macroglobulinemia, sickle cell disease, and certain forms of leukemia, rarely cause sudden hearing loss $[1,2]$.

\section{Evaluation}

The evaluation consists in the detection and quantification of hearing loss and in determining the etiology (above all, of the reversible causes).

\section{Anamnesis}

\section{Antecedents of the Current Illness}

They must verify that the loss is sudden and not chronic. It should reveal whether the loss is unilateral or bilateral and if 
there is a current acute event (eg, head injury, barotrauma [above all diving injury], infectious diseases). Among the accompanying symptoms of importance, other otic symptoms (eg, tinnitus, secretion), vestibular symptoms (eg, disorientation in the dark, vertigo) and other neurological symptoms (eg, headache, weakness) are mentioned. or asymmetry of the face, abnormal sensation of taste).

\section{Review of Devices and Systems}

You should look for symptoms of the possible causes, such as migratory and transitory neurological deficiencies (multiple sclerosis) and ocular irritation and redness (Cogan syndrome).

\section{Personal History}

Should investigate about known infection with HIV or syphilis and risk factors for them (eg, multiple sexual partners, unprotected sex). Family history should record close relatives with hearing loss (suggesting a congenital fistula). In the pharmacological background, you should specifically ask about the past or current use of ototoxic drugs and if the patient has insufficiency or known renal failure.

\section{Physical Exam}

a) The exam focuses on the ears and hearing and on the neurological examination.

b) The tympanic membrane is inspected for perforation, discharge, or other injuries. During the neurological examination, attention must be paid to the cranial nerves (especially V, VII and VIII) and to the vestibular and cerebellar function, because anomalies in these areas usually occur with brainstem tumors and the cerebellopontine angle.

c) The Weber and Rinne tests require a tuning fork to differentiate driving hearing loss from the sensorineural hearing loss.

d) In addition, the eyes are examined for redness and photophobia (possible Cogan syndrome), and the skin to assess the presence of rash (eg, viral infection, syphilis).

\section{Alarm Signs}

The findings that raise concern are

a) Alterations of cranial nerves (other than those involved in hearing loss).

b) Significant asymmetry in speech understanding between the two ears. Other neurological signs and symptoms (eg, motor weakness, aphasia, Horner's syndrome, abnormal perception of sensations or temperature).

\section{Interpretation of the Findings}

a) Traumatic, ototoxic and some infectious causes are usually evidenced clinically. A patient with perilymphatic fistula can hear an explosive sound in the affected ear when the fistula occurs and may also have sudden vertigo, nystagmus, and tinnitus. b) Focal neurological alterations are of special concern. Often, the cranial pairs V and VII are affected by tumors that affect the 8th cranial nerve, so that there is a loss of facial sensation and some weakness to tighten the jaw (V) and a hemifacial weakness and taste alterations. (VII) that suggest an injury in that area.

c) Fluctuating unilateral hearing loss accompanied by a blocked ear, tinnitus and vertigo also suggests Ménière's disease. Systemic symptoms suggestive of inflammation (eg, fever, rash, joint pains, mucous lesions) should raise the suspicion of a hidden infection or autoimmune disorder.

d) Complementary studies

e) Audiometry

f) RM and TC

Patients with sudden deafness should undergo an audiogram and, unless the diagnosis is clear regarding an acute infection or drug toxicity, most doctors indicate gadolinium-enhanced MRI to diagnose non-obvious causes, particularly in unilateral hearing loss. MRI should also be performed for patients with an acute traumatic cause. A perilymphatic fistula is typically suspected in the presence of a triggering event (eg, excessive distension, barotrauma), and the test can be performed using positive pneumatic pressure that triggers eye movements (nystagmus). CT of the temporal bones is usually indicated to show the bony characteristics of the inner ear and may help to identify congenital anomalies (eg, dilation of the vestibular aqueduct), fractures of the temporal bone due to trauma or erosive processes (p. eg, cholesteatoma).

Patients with risk factors or symptoms suggesting causes should be given appropriate tests based on clinical assessment (eg, serologic tests for possible HIV infection or syphilis, coagulation profile and complete blood count for blood disorders, erythrocyte sedimentation rate and antinuclear antibodies for vasculitis).

\section{Treatment}

The treatment of sudden hearing loss should be directed to the causal disorder when it is known. Fistulas require exploration and surgical repair when bed rest does not control the symptoms.

a) In viral and idiopathic cases, hearing returns to normal in about $50 \%$ of patients and partially recovers in others.

b) In patients who recover their hearing, the improvement usually occurs within 10 to 14 days.

c) The recovery of an ototoxic medicine varies a lot depending on the drug and its dosage. With some medications (eg, aspirin, diuretics), hearing loss resolves within 24 hours, while other drugs (eg, antibiotics, chemotherapy drugs) usually cause permanent hearing loss if the safe doses have been exceeded. 
In patients with idiopathic loss, many physicians empirically indicate a corticosteroid course (typically $80 \mathrm{mg} / \mathrm{kg}$ prednisone orally once a day for 7 to 14 days, followed by a dose reduction for 5 days). Corticosteroids can be administered orally and / or by trans tympanic injection. Direct trans tympanic injection avoids the systemic side effects of oral corticosteroids and is equally effective except in profound hearing loss ( $>90$ decibels). There are data that show that the use of oral and intratympanic corticosteroids leads to better results than either of the two alone. Although doctors often give antiviral drugs effective against herpes simplex (eg, valaciclovir, famciclovir), the data show that this type of medication does not affect the results of the test. Some limited data suggest that hyperbaric oxygen therapy may be beneficial in the sudden loss of idiopathic hearing.

\section{Key Concepts}

a) The majority of cases are idiopathic.

b) Some cases have an obvious cause (eg, very severe trauma, acute infection, drugs).

c) Some cases represent unusual manifestations of treatable disorders.

\section{References}

1. Stachler RJ, Chandrasekhar SS, Archer SM, et al. (2012) Clinical practice guideline: Sudden hearing loss. Otolaryngol Head Neck Surg 146 (3 Suppl): S1-35.

2. John K Niparko, Tiber Alpert Professor and Chair, USC Tina and Rick Caruso Department of Otolaryngology Head and Neck Surgery, Keck School of Medicine, University of Southern California; President, USC Care, Keck School of Medicine, University of Southern California.

\section{Your next submission with Juniper Publishers} will reach you the below assets

- Quality Editorial service

- Swift Peer Review

- Reprints availability

- E-prints Service

- Manuscript Podcast for convenient understanding

- Global attainment for your research

- Manuscript accessibility in different formats

( Pdf, E-pub, Full Text, Audio)

- Unceasing customer service

Track the below URL for one-step submission https://juniperpublishers.com/online-submission.php 